\title{
Tensile and Flexural properties of MMT- clay/ Unsaturated Polyester using Robust Design Concept
}

\author{
N. Rajini ${ }^{1 a^{*}}$, J.T. Winowlin Jappes ${ }^{2, b}$, S.Rajakarunakaran ${ }^{1, c}$ and I.Siva ${ }^{1, d}$ \\ ${ }^{1}$ Department of Mechanical Engineering, Kalasalingam University, Tamilnadu, India \\ ${ }^{2}$ Department of Mechanical Engineering, Cape Institute of Technology, Tamilnadu, India \\ Email: ${ }^{1 a^{*}}$ rajiniklu@gmail.com (corresponding author), ${ }^{b}$ winowlin@yahoo.com, \\ csrajakarunakaran@yahoo.com, ${ }^{\mathrm{d}}$ isiva@ymail.com
}

Key Words: Nano-Composite, Nano-clay, Robust design, XRD, AFM

\begin{abstract}
The effect of Nano-clay on the mechanical properties of Isophthalic unsaturated polyester was studied with the help of robust design Concept. Organo modified MMT nano-clay (Nanomer 1.31PS) was used as reinforcement. The weight percentage of nano-clay, impeller blade design, mixing hours and mixing speed were taken as control factors. In Taguchi design of experiments, L9 orthogonal array was employed to investigate the effect of control factors on mechanical properties such as tensile and flexural strength. X-ray diffraction (XRD) and Atomic force microscopy (AFM) results show the intercalation /exfoliation of clays in the polyester matrix.
\end{abstract}

\section{Introduction}

Polymer nanocomposite is a new kind of composite material having any one constituent in nano dimension. Nowadays polymer nano-composite (PNC) attracts a lot of research's due to its multi functional features like high specific strength, flame resistance, enhanced mechanical properties and all these required for current military, aerospace and automobile industries [1-4]. The improvement in the property is achieved due to large surface area, high aspect ratio and high crystallinity of the clay nano particles that are all indirectly related to the dispersion of the nano particle [5]. Uniform dispersion of these nano sized fillers (nano clay) produces an ultra large interfacial area per volume between the nano particle and matrix. 
Asma-yasmin et al. [6] showed the effect of the clay concentration on the tensile properties of epoxy clay nano composite and concluded that the improved properties can be obtained at low filler content $(<5 \mathrm{wt} \%)$. Vaia et al. [7] studied the degree of exfoliation; it could be improved through the aid of conventional shear devices such as extruders, mixers, ultrasonic agitators, shear mixture etc. Kornmann et al. [8, 9] investigated the polyester composite hybrid with nano-clay, and they improved the mechanical properties especially the fracture toughness of the material doubled when hybrid with nano-clay. Few researchers used Taguchi technique to optimize the process parameters in polymer nanocomposites [10-14]. In these limited literatures, they focused mainly on the weight percentage of nanoclay, mixing time and type of nanoclay. But the stirring which forms different vortices would be important for the dispersion. Hence in this work the effect of blade design is selected as one of the control factors. The effect of process variables, such as the weight percentage of nano-clay, impeller blade design, mixing hours and impeller speed on the dispersion of nano clay in the matrix and properties of unsaturated polyester/MMT clay nanocomposites under room temperature curing were studied.

\section{Experimental details}

Materials Used. Unsaturated isophthalic polyester resin in the form of liquid was used as a matrix, procured from Vasavibala resins (P) Ltd, Chennai. The molecular weight of the unsaturated polyester is 2800. Organo- modified montmorillonite nanoclay in the form of powder (MMT-modified with 15-35 wt $\%$ Octadecylamine \& $0.5-5 \mathrm{wt} \%$ aminopropytriethoxysilane) was used for reinforcement. The commercially available organo- modified MMT nanoclay (Nanomer 1.31 PS) was procured from Sigma Aldrich. One weight percentage of Methyl Ethyl Ketone Peroxide (MEKP) and Cobalt Naphthenate has been used as a catalyst and accelerator for room temperature curing and they were obtained from Vasavibala resins (P) Ltd, Chennai. 
Nanocomposite preparation. Nanocomposites were prepared by varying the organo- modified clay content, impeller blade design, mixing hours and impeller speed. In this work, mechanical high shear mixer was used to distribute and exfoliate the clay nano-particles in the polyester matrix. $300 \mathrm{ml}$ of polyester resin was taken in a glass beaker. Calculated amount of organic clay was added to polyester in room temperature to produce nanocomposite. The final product was collected from the high shear mixer and was allowed to degass in a vacuum desiccator at negative pressure of 20 $\mathrm{Hg} / \mathrm{mm}$ for one hour. In the $500 \mathrm{ml}$ glass beaker, the burette controller was fused at the bottom and this apparatus was used to separate the bubble layer, since the pure layer of resin is settled down (Fig. 1-a and 1-b). The specimen with the mold was allowed to cure at room temperature for next 24 hours. The post curing was also done at $60{ }^{\circ} \mathrm{C}$ for $3 \mathrm{~h}$ in hot air oven.

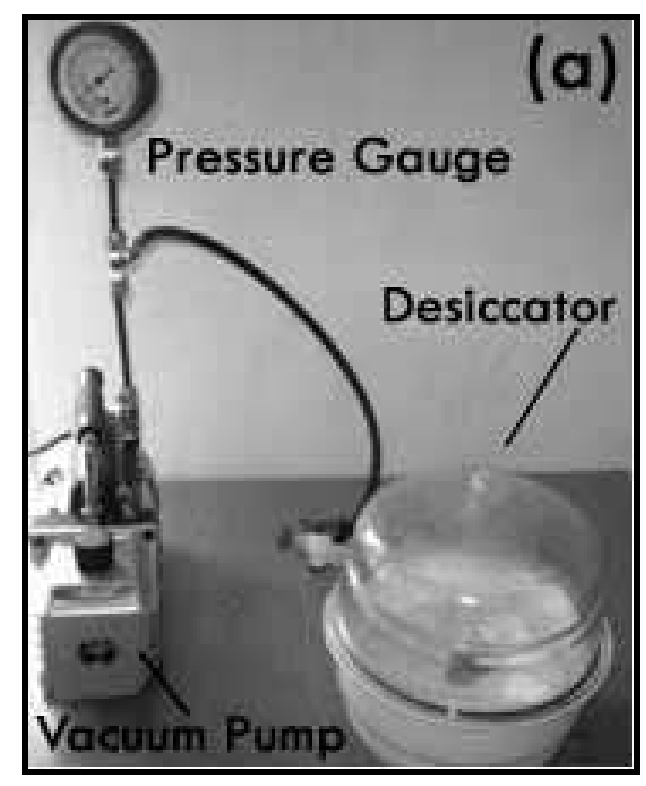

Fig. 1. (a) Desiccator with vacuum

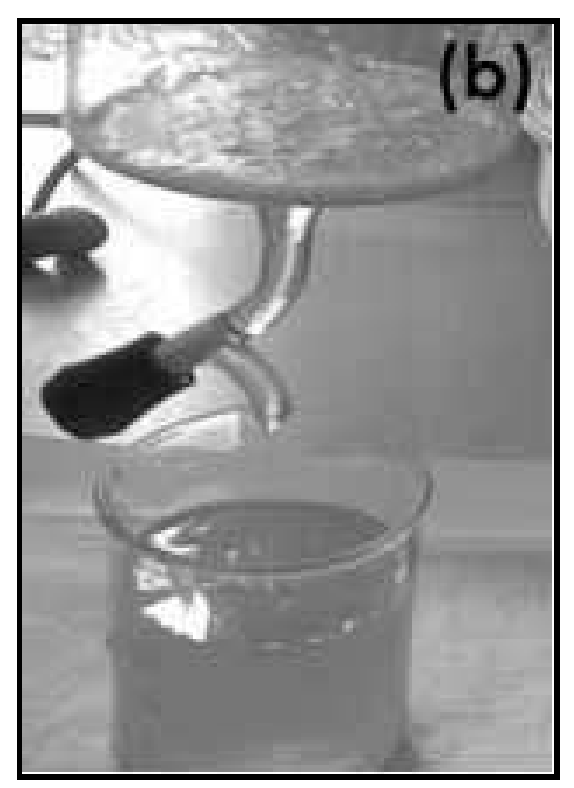

Fig. 1 (b) Air bubbles separator pump

Tensile and Flexural Testing. Tensile and flexural testing were conducted in 3 Ton computer controlled Universal Testing Machine. Specimens for tensile test and flexural test were prepared according to the ASTM - D638 (Type I) and D790 respectively. In flexural testing, three-point bending at room temperature was performed. In three-point bending, the load was placed centrally between the supports. Five specimens were tested in each case and the average value was reported. 
Dispersion Studies. Dispersion of nanoclay with matrix was studied and ensured with the help of Xray diffraction (XRD) and Atomic Force Microscope (AFM). In XRD step scanning was employed with a scanning rate of $2 \%$ min with $\mathrm{Cu}-\mathrm{K} \alpha$ radiation using SHIMADZU, XD-DI X-ray

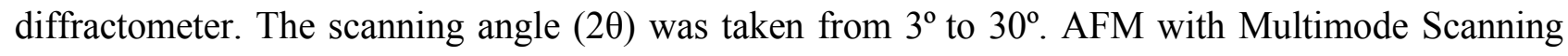
Probe Microscope (NTEGRA, NT-MDT, Moscow) equipped with a DS 95-50-E scanner and an AC probe were used.

\section{Results \& discussions}

Robust Design Concepts. Based on the literature and preliminary works, the following control factors were identified as key factors which affect the dispersion of nanocomposite. Mixing time, mixing speed, the weight percentage of nanoclay and blade design has been selected as control factors. Fig. 2 shows the photograph of blades used for this study.

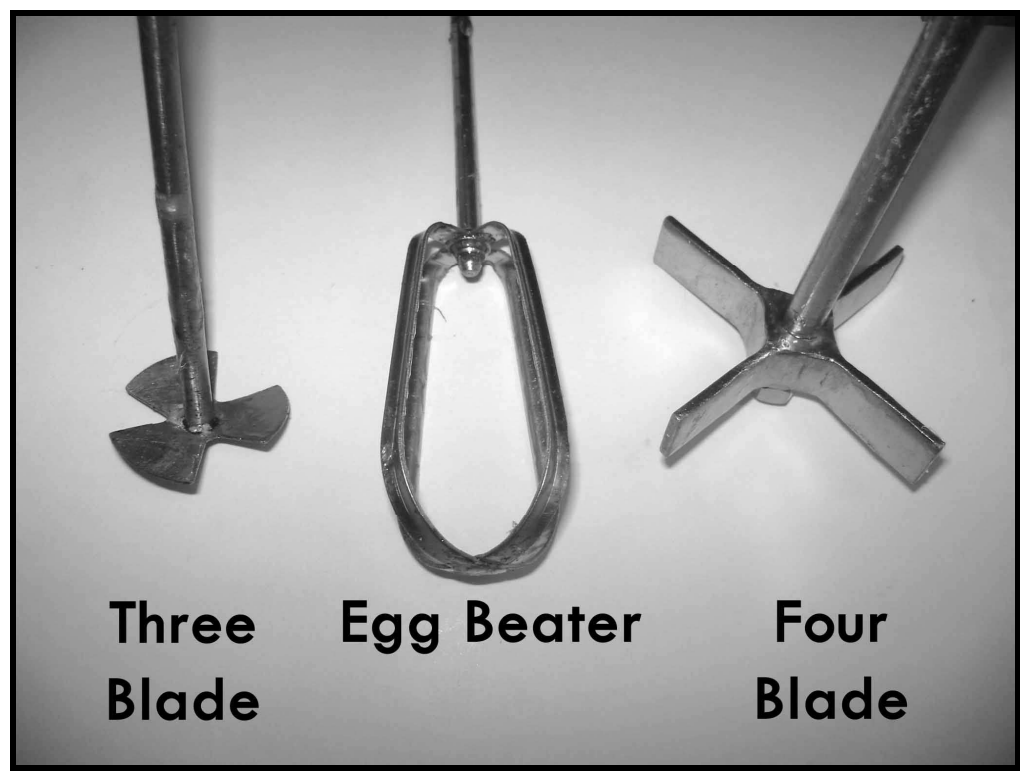

Fig. 2. Different designs of Blade

After deciding the independent variables, the numbers of levels for each variable were decided. The selection of the level numbers depends on the trend in which the parameter influences the output responses (Table 1). 
Table 1. Levels of the variables used in the experiment.

\begin{tabular}{|l|c|c|c|c|}
\hline \multicolumn{1}{|c|}{ Control Factors } & Symbol & Level 1 & Level 2 & Level 3 \\
\hline Mixing Speed (Rpm) & $\mathrm{S}$ & 500 & 750 & 1000 \\
\hline Mixing Time ( Min) & $\mathrm{T}$ & 60 & 120 & 180 \\
\hline Blade Design & $\mathrm{B}$ & 4 Blade & 3 Blade & Egg Beater \\
\hline Clay content (Wt \%) & $\mathrm{C}$ & 1 & 2 & 3 \\
\hline
\end{tabular}

Array selection was based on the number of parameters and the number of levels. In this investigation, 4 factors and 3 levels have been identified. Hence $\mathrm{L}_{9}$ orthogonal array was selected. The standard layout of $\mathrm{L}_{9}$ orthogonal array is given in Table 2.

Table 2. Orthogonal Array for L9 Taguchi design.

\begin{tabular}{|c|c|c|c|c|}
\hline Ex. No & A & B & C & D \\
\hline 1 & 1 & 1 & 1 & 1 \\
\hline 2 & 1 & 2 & 2 & 2 \\
\hline 3 & 1 & 3 & 3 & 3 \\
\hline 4 & 2 & 1 & 2 & 3 \\
\hline 5 & 2 & 2 & 3 & 1 \\
\hline 6 & 2 & 3 & 1 & 2 \\
\hline 7 & 3 & 1 & 3 & 3 \\
\hline 8 & 3 & 2 & 1 & 1 \\
\hline 9 & 3 & 3 & 2 & \\
\hline
\end{tabular}

In Table 2, first,second, third and fourth columns were assigned to mixing speed (S), mixing hour (T), design of blades and weight percentage of clay (wt \%). The next step was to conduct the matrix experiment and record the results.

After the experiments have been conducted, the optimal test parameter configuration within the experimental design must be determined. To analyze the results, the Taguchi method uses a statistical measure of performance called signal to-noise $(\mathrm{S} / \mathrm{N})$ ratio. The $\mathrm{S} / \mathrm{N}$ ratio which was developed by Dr. Taguchi, is a performance measure to choose control levels that best cope with noise $[12,13]$. In its simplest form, the $\mathrm{S} / \mathrm{N}$ ratio is the ratio of the mean (signal) to the standard deviation (noise). The $\mathrm{S} / \mathrm{N}$ equation depends on the criterion for the quality characteristic to be 
optimized [12]. While there are many different possible $\mathrm{S} / \mathrm{N}$ ratios, in this investigation 'Larger the better characteristic' was selected based on the requirement. Equation (1) represents larger the better quality characteristic,

$\frac{S}{N}=-10 \log \frac{1}{n}\left(\sum \frac{1}{y^{2}}\right)$

Where $n$ is the number of observations for every experiment and $y$ is the observed data from the experiment.

Tensile Strength. Experiments were conducted as per the Taguchi L 9 orthogonal array, however, the test runs were selected at random, to avoid systematic error creeping into the experimental procedure.

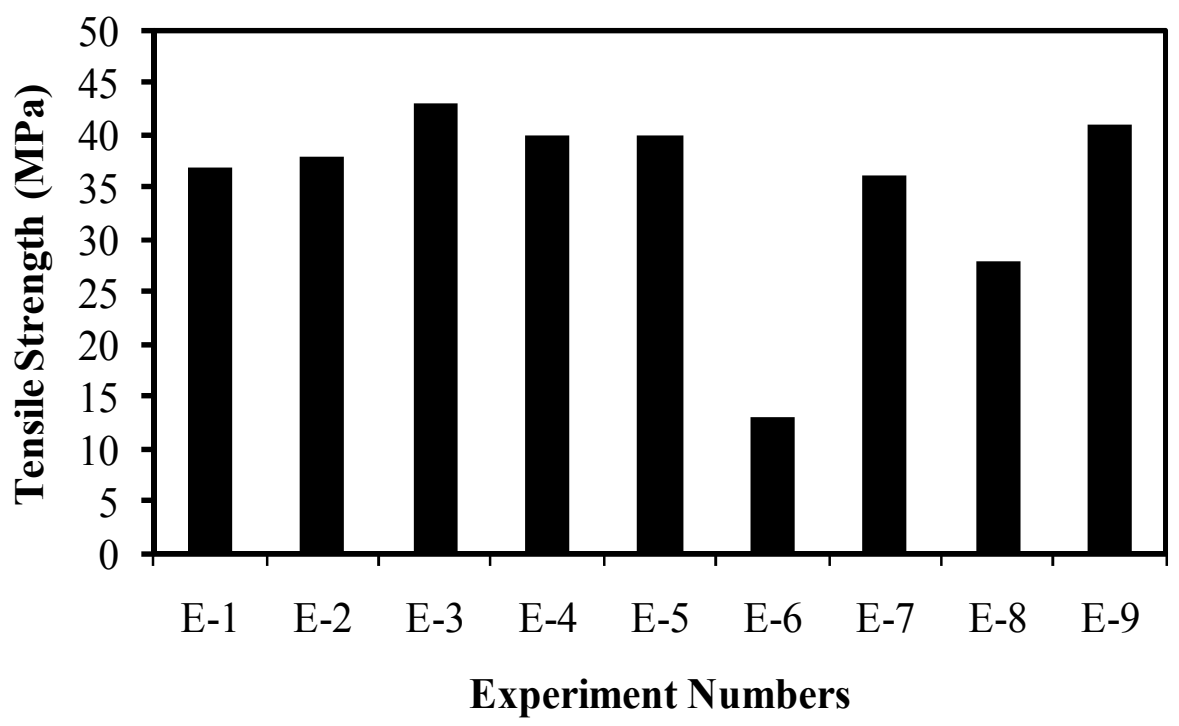

Fig. 3. Tensile strength based on $\mathrm{L}_{9}$ orthogonal array

Fig. 3 shows the variation in tensile strength for all the experiments, it shows the influence of the control factors on the output response. In experiment number six, the value of tensile strength is reduced drastically which could be due to the increase in viscosity of the liquid has not allowed the entrapped air outside from the mixture. Viscosity increased because of the more shear force which 
breaks the clay by decreasing aspect ratio of clay platelet. The experiment numbers 2,4 and $9^{\text {th }}$ were shown more or less equal tensile strength value where the sample was fabricated by three blade design. To find the optimum value of output response, the $\mathrm{S} / \mathrm{N}$ ratio was calculated for all the experiments with the help of MINITAB 14 (a statistical software tool), larger-the-better characteristic formula has been used to find the $\mathrm{S} / \mathrm{N}$ ratio from which the combination of optimum factors to enhance the mechanical properties of formulated nanocomposites was identified.

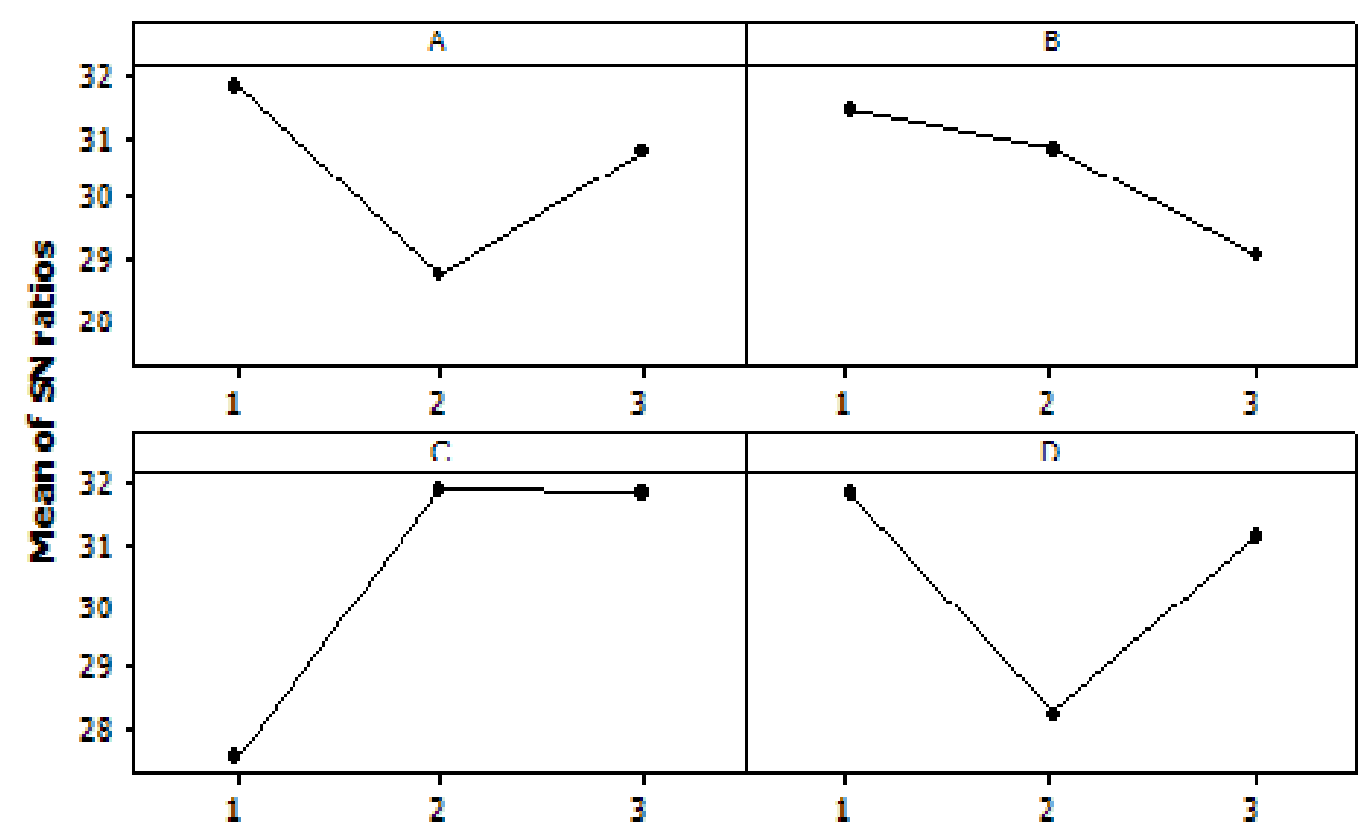

Fig. 4. Average $\mathrm{S} / \mathrm{N}$ ratio for control factors

Fig. 4 shows the average $\mathrm{S} / \mathrm{N}$ ratio for control factors. Since larger the $\mathrm{S} / \mathrm{N}$ ratio will lead to the smaller value of variation (noise). The maximum values of average $\mathrm{S} / \mathrm{N}$ ratios were taken as the optimum values for the parameters. From the graph plotted from the experimental data shown in figure, it is inferred that the values of, speed S1 (500 rpm), time T1 (60 min), blade design B2 (three blade) and weight percentage $\%$ of clay $\mathrm{C} 1(1 \mathrm{wt} \%)$ were identified as optimal values. The contribution of each parameter on tensile strength is given in Table 3. 
Table 3: Contribution ratio for Tensile Strength

\begin{tabular}{|l|l|c|c|c|c|}
\hline $\begin{array}{l}\text { Mechanical } \\
\text { Properties }\end{array}$ & Factors & $\begin{array}{c}\text { Mixing } \\
\text { Speed (S) }\end{array}$ & $\begin{array}{c}\text { Mixing } \\
\text { Hour } \\
\text { (T) }\end{array}$ & $\begin{array}{c}\text { Blade } \\
\text { design } \\
\text { (B) }\end{array}$ & $\begin{array}{c}\text { Wt \% of } \\
\text { clay (C) }\end{array}$ \\
\hline $\begin{array}{l}\text { Tensile } \\
\text { Strength } \\
(\mathrm{MPa})\end{array}$ & $\begin{array}{l}\text { Contribution } \\
\text { Ratio (\%) }\end{array}$ & 17.13 & 11.37 & $\mathbf{4 4 . 9 8}$ & 26.52 \\
\cline { 2 - 6 } & $\begin{array}{l}\text { Cumulative } \\
\text { Contribution } \\
\text { Ratio (\%) }\end{array}$ & 17.13 & 28.50 & 73.48 & 100 \\
\hline
\end{tabular}

From this table, Blade design, \% of Clay and Mixing speeds are identified as significant factors affecting tensile strength. The confirmation test was conducted for the optimum factors according to the level settings of S1 (500 Rpm), T 1(60 Min), B2 (Three Blade) and C 1(1wt \%), the tensile strength for the same was found to be $45 \mathrm{MPa}$ which were higher than all other tested values.

Flexural Strength. The flexural testing was conducted for all the nine experiments according to ASTM 790 using Universal testing machine with the crosshead speed of $2 \mathrm{~mm} / \mathrm{min}$. The volume of the molded specimen is $127 \times 12.7 \times 3 \mathrm{~mm}^{3}$. The span length between the supports was fixed at 48 $\mathrm{mm}(16: 1)$. Fig. 5 shows the variation in flexural strength for all the experiments. In experiment number six, the value of flexural strength has been reduced drastically since the formation of high viscous mixture. The deformation took place with a small amount of load for longer deformation. 


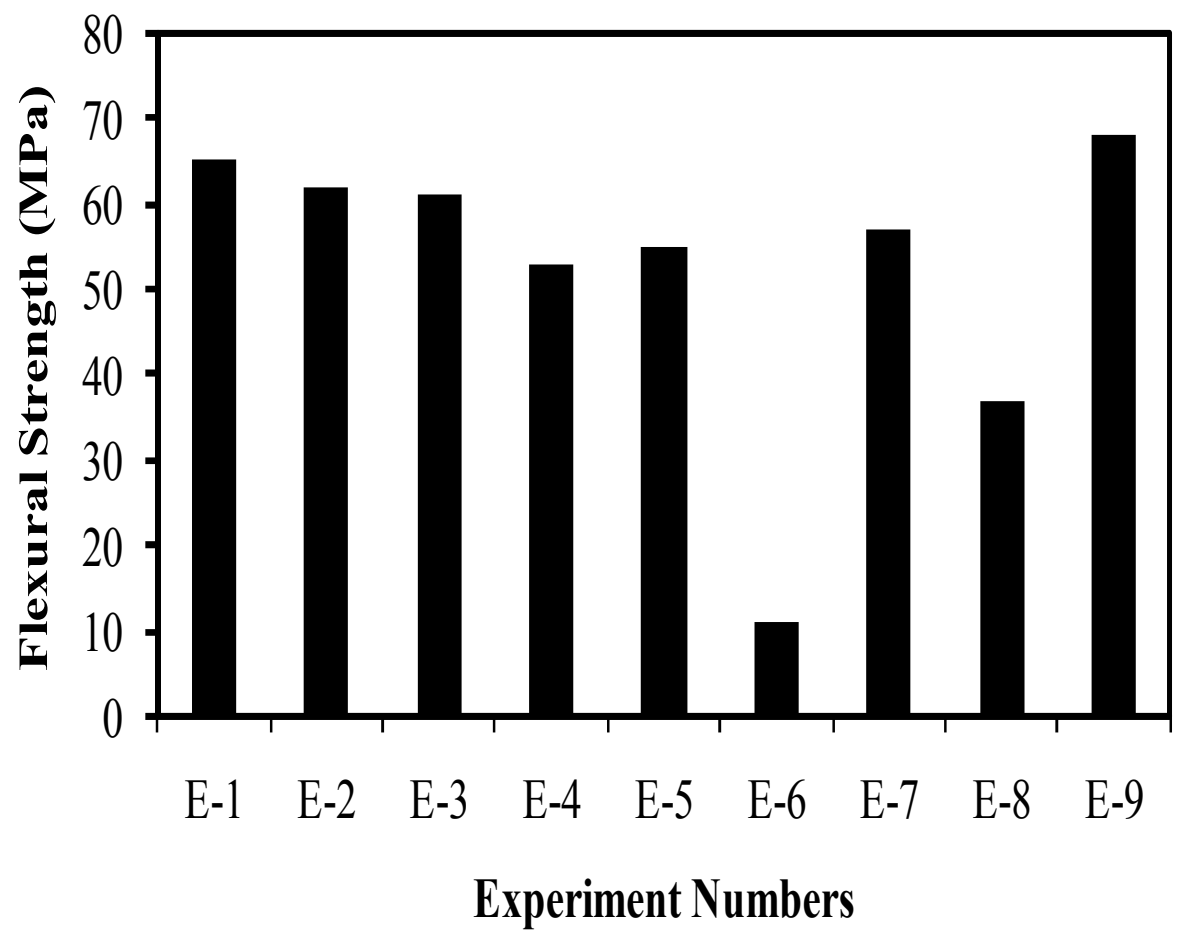

Fig. 5. Flexural strength based on $\mathrm{L}_{9}$ orthogonal array

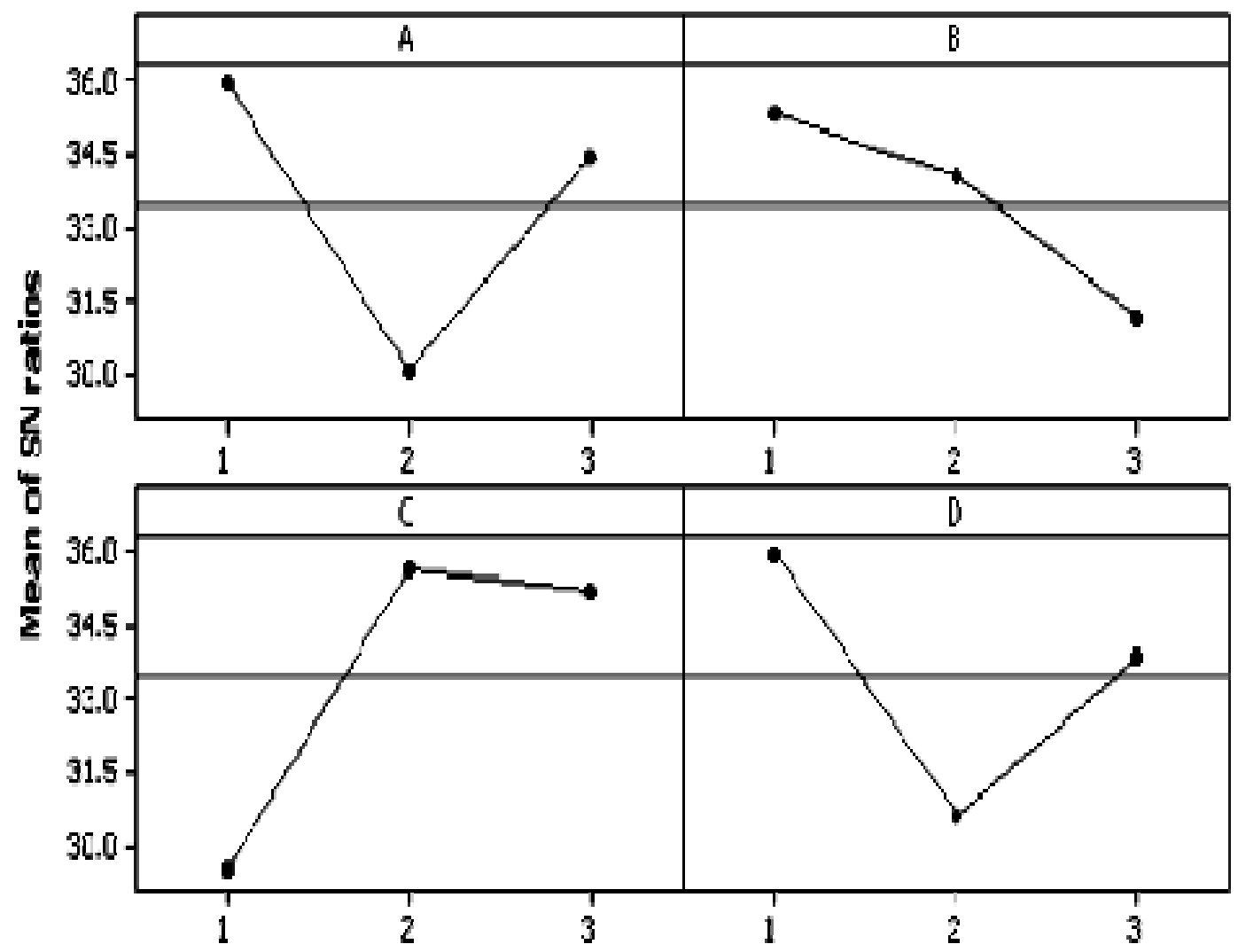

Fig. 6. Average $\mathrm{S} / \mathrm{N}$ ratio for control factors. 
Fig. 6 shows the average $\mathrm{S} / \mathrm{N}$ ratio of control factors for flexural strength. From the plotted experimental data, shown in this figure, it is inferred that the values of speed S1 $(500 \mathrm{rpm})$, time T1 (60 min), blade design B2 (three blade) and weight percentage \% of clay C1 (1 wt \%) were identified as optimal values. The contribution of each parameter on flexural strength is given in Table 4. From this table, blade design, $\%$ of Clay and mixing speeds are identified as significant factors affecting flexural strength. Flexural strength for the optimal parameters was found to be $70 \mathrm{MPa}$.

Table 4: Contribution ratio for Flexural Strength

\begin{tabular}{|l|l|c|c|c|c|}
\hline $\begin{array}{l}\text { Mechanical } \\
\text { Properties }\end{array}$ & \multicolumn{1}{|c|}{ Factors } & $\begin{array}{c}\text { Mixing } \\
\text { Speed (S) }\end{array}$ & $\begin{array}{c}\text { Mixing Hour } \\
\text { (T) }\end{array}$ & $\begin{array}{c}\text { Blade design } \\
\text { (B) }\end{array}$ & $\begin{array}{c}\text { Wt \% of clay } \\
\text { (C) }\end{array}$ \\
\hline $\begin{array}{l}\text { Flexural } \\
\text { Strength } \\
(\mathrm{MPa})\end{array}$ & $\begin{array}{l}\text { Contribution } \\
\text { Ratio (\%) }\end{array}$ & 28.04 & 14.22 & $\mathbf{3 5 . 9 9}$ & 21.75 \\
\cline { 2 - 6 } & $\begin{array}{l}\text { Cumulative } \\
\text { Contribution } \\
\text { Ratio (\%) }\end{array}$ & 28.04 & 42.26 & 78.25 & 100 \\
\hline
\end{tabular}

XRD Analysis. Fig. 7 show the diffractograms of pure nano-clay and nano-clay reinforced polyester X-ray (nine samples which are produced based on Taguchi experimentation). From the diffractogram for pure nanoclay, a definite sharp peak at $4.5^{\circ}(2 \theta)$ was observed as crystallized nanoclay. During hybridization, in all the experiments good dispersion of nano-clay with matrix and this could be observed from the suppressed peak which was seen in the pure nano-clay in (001) plane. However Taguchi experiments showed better dispersion thereby improved tensile and flexural performance. This is indicating the presence of amorphous phase and exfoliation of the clay galleries in the matrix system [15-18]. This shows that the interlayer distance of organo modified clay layers is randomly dispersed in the polymer matrix. 


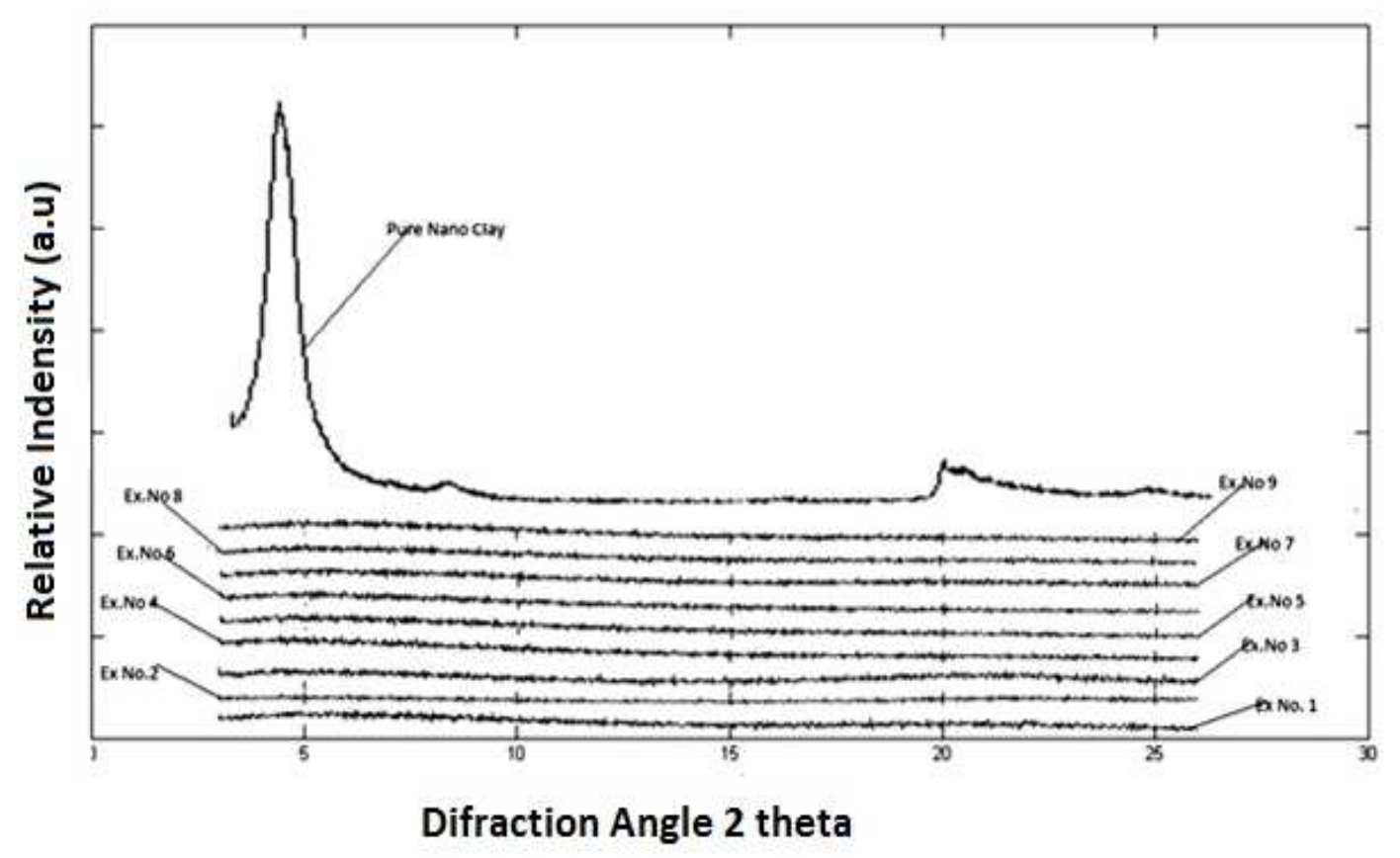

Fig. 7. XRD Pattern of MMT clay with nine experiments according to L9 orthogonal array

AFM Analysis. For AFM analysis, the sample prepared in optimized condition (speed of $500 \mathrm{rpm}$, time $-60 \mathrm{~min}$, three blades and $1 \mathrm{wt} \%$ of clay) was selected. The phase images of the optimized nanocomposite have been used to study polymer crystallization and nanoclay dispersion. Measurements were carried out in air, at ambient conditions. Phase and height images were recorded simultaneously. From the Fig. $8(\mathrm{a}, \mathrm{b})$, three different appearances of shading was found: One in dark black; it is expected to be pure matrix and the second shadow is light black which could be the interface between nanoclay and the matrix and pure white is speculated to the presence of MMT nanoclay $[19,20]$. This AFM image clearly shows that the uniform distribution of nanoclay in most of the region of the matrix. Fine clays can be seen in the AFM three-dimensional phase image of the optimized nanocomposite sample Fig. 8 (b). 

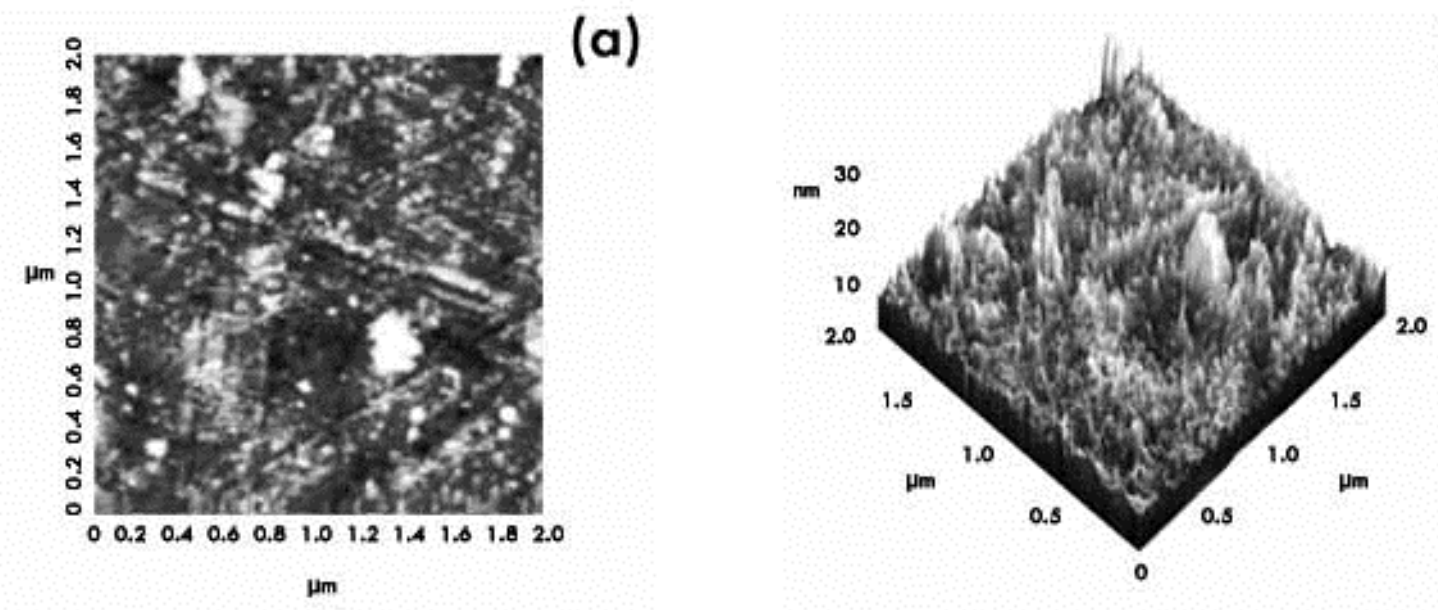

(b)

Fig. 8. (a). The AFM phase image of MMT clay/UP Nanocomposites, (b) Three-dimensional image by AFM showing well distributed clay in the matrix.

\section{Conclusions}

From the experimentation, the optimum process parameters such as weight percentage of nano-clay, impeller blade design, mixing hours and impeller speed on tensile and flexural strengths were identified. Speed of $500 \mathrm{rpm}$, time - $60 \mathrm{~min}$, three blades and $1 \mathrm{wt} \%$ of clay were found to be better in order to improve the properties. The blade design was identified as the main control factor to improve the properties.

\section{Acknowledgements}

The authors wish to thank the Department Science and Technology, India for the funding through SR/FTP/ETA-92/2009 project, and also the Center for Composite Materials, Department of Mechanical Engineering, Kalasalingam University for their kind permission to carry out the preparation and testing of the composites. 


\section{References}

[1] P. Jawahar, M. Balasubramanian, Thermal, Mechanical and Water Barrier Properties of Clay Unsaturated Polyester Nanocomposites, International Journal of Plastic Technology, 9 (2005) 472-481.

[2] P.K. Kushwaha, R. Kumar, Reinforcing Effect of Nanoclay in BambooReinforced Thermosetting Resin Composites, Polym. -Plast. Technol. Eng. 49 (2011)127-135.

[3] P. Jawahar, M. Balasubramanian, Preparation and properties of polyester-based nanocomposites gel coat system, J. Nanomater. 50 (2006) 1-7.

[4] K.K. Maniar, Polymeric Nanocomposites: A Review, Polym. -Plast. Technol. Eng. 43 (2004) 427- 443.

[5] J.H. Koo, Polymer Nanocomposites: Processing, Characterization, And Applications, first edition, McGraw-Hill, 2006.

[6] A. Yasmin, J.L. Abot, L.M. Daniel, Processing of clay/epoxy nanocomposites by shear mixing, Scr. Mater. 49 (2001) 81-86.

[7] R. A. Vaia., K.D Jandt, E.J, Kramer, E. Pgianaeles. Microstructure evaluation of meltinternational polymer-organically modified layered silicate nano composites, Chem. Mater. 8 (1996) 2628-35.

[8] X. Kornmann, L.A. Berglund, J. Sterte, E.P. Giannelis, Nanocomposites based on montmorillonite and unsaturated polyester, Polym. Eng. Sci. 38 (1998)1351-1358.

[9] X. Kornmann, L. A. Berglund, R. Thomann, R. Mulhaupt, J. Finter, High performance epoxy layered silicate nanocomposites, Polym. Eng. Sci. 42 (2002) 1815-1826. 
[10] Y. Dong, D. Bhattacharyya, P.J. Hunter, Optimization on property enhancement of polypropylene/organoclay nanocomposites, $16^{\text {th }}$ International conference on composite materials, Japan, 1-7, 2007.

[11] R. Khosrokhavar, G. Naderi, M.H.R. Ghoreishy, Effect of processing on PP/EPDM/Organoclay Nanocomposites Using Taguchi Analysis Method, Iran Polym. J. 20 (2011) 41-53.

[12] M. Joulazadeh, A.H. Navarchian, Effect of process variables on mechanical properties of polyurethane/clay nanocomposites, Polym. Adv. Tech. 21(2010) 263-271.

[13] H. Suherman, J. Sahari, A. B. Sulong, Optimization Mixing Parameters on the Electrical Conductivity of Polymer Nanocomposites Based on the Taguchi Method, Applied Mechanics and Materials, 31(2011) 52-54.

[14] C.-J. Tzenga, Y.-K. Yanga, M.-H. Hsieha, C.-Y. Chena, Adaptive Adjustment of Injection Molding Process for Mechanical Characteristics Using the Taguchi Method and Response Surface Methodology, Polym. -Plast. Technol. Eng. 50 (2011) 552 - 563.

[15] T.P. Mohan, M.R. Kumar, R. Velmurugan , Thermal, mechanical and vibration characteristics of epoxy-clay nanocomposites, J. Mater. Sci. 41(2006) 5915-5925.

[16] S.K. Nayak, S. Mohanty, S.K. Samal, Effect of Clay Types on the Mechanical, Dynamic Mechanical and Morphological Properties of Polypropylene Nanocomposites, Polym. -Plast. Technol. Eng. 48 (2009) 976-988.

[17] D. Debnatha, K.A. Dhibara, B.B. Khatuaa, Studies on the Morphology and Properties of PMMA-Organoclay Nanocomposites with Reference to the Manufacturing Techniques, Polym. -Plast. Technol. Eng, 49 (2010)1087-1094. 
[18] M. Kannana, S.S. Bhagawana, J. Kuruvilla, S. Thomas, Mechanical Properties and Morphology of Nanoclay-Filled Different TPU/PP Blends, Polym. -Plast. Technol. Eng, 48 (2009) 871- 876.

[19] F. Hermati, H. Garmbi, Compatibilised LDPE/LLDPE/NANOCLAY Nanocomposites: Strutural, Mechanical and thermal properties, Can. J. Chem. Eng. 89 (2011) 187-195.

[20] A. Ganguly, A. K.Bhowmick, Effect of modification on morphology and properties of styrene-(ethylene-co-butylene)-styrene triblock copolmer and its montmorillonite clay-based nanocomposites, J. Mater Sci. 44 (2008) 903-918. 